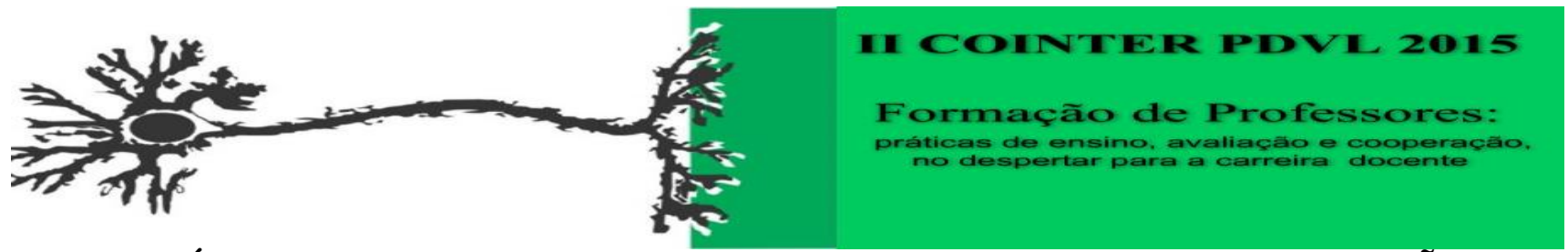

\title{
A POLÍTICA EDUCACIONAL DO PACTO NACIONAL PELA ALFABETIZAÇÃO NA IDADE CERTA NO ATUAL CONTEXTO DA GLOBALIZAÇÃO
}

\author{
Apresentação: Comunicação Oral \\ JÉSSICA SANTOS DO NASCIMENTO - jessik.cdf@gmail.com; \\ KARINA SANTOS DO NASCIMENTO
}

\begin{abstract}
Resumo: Este presente trabalho teve por objetivo analisar os objetivos dos cadernos de formação do Pacto Nacional pela Alfabetização na Idade Certa (PNAIC), que tem por finalidade alfabetizar as crianças até os oito anos de idade no atual contexto de globalização. A pesquisa nos interessou porque em pleno século XXI, verificamos ainda a necessidade de altos investimentos em uma questão que é de ordem básica, que devia ter cido sanada, a alfabetização. O contexto de globalização tem orientações para as políticas educacionais com base nos preceitos neoliberais, fomentando a centralização da proposta curricular por meio das avaliações em larga escala, com finalidades a inserção no mercado de trabalho. O caminho teórico-metodológico se constitui pela abordagem qualitativa, realizada por analise de conteúdos dos cadernos de formação. Tivemos como adiantamento de resultados que os cadernos do PNAIC mesmo envolvendo a discussão de inclusão dos direitos de aprendizagens e, o debate de inclusão e integração nos seus sentidos mais amplos, foi instituído em tempos de globalização, carrega o fosso da segregação, privilegiando o português e a matemática.
\end{abstract}

Palavras-Chaves: alfabetização, programa educacional, globalização, PNAIC.

\section{Introdução}

Este presente trabalho teve por objetivo analisar os objetivos dos cadernos do Pacto Nacional pela Alfabetização na Idade Certa (PNAIC). O programa surgiu e vem se desenvolvendo no atual contexto de globalização. O objetivo do programa é alfabetizar as crianças até os oito anos de idade em pleno século XXI, uma questão no qual impulsionou a necessidade de investimentos altos em um assunto que é de ordem básica, inclusive estar alfabetizado é pré-requisito para o prosseguimento das etapas educacionais. Mesmo o programa envolvendo a discussão de inclusão dos direitos de aprendizagens e, abordando entre outros os Cadernos do Campo e outro Caderno Especial, integrando o debate de inclusão nos seus sentidos mais amplos, foi instituído em tempos de globalização. A globalização segundo Santos:

Froebel, Heinrichs e Kreye (1980) foram provavelmente os primeiros a falar, no inicio da década de oitenta, da emergência de uma nova divisão internacional do trabalho, baseada na globalização da produção levada a cabo pelas empresas multinacionais, gradualmente convertidas em actores centrais da nova economia mundial. Os traços principais desta nova economia mundial são os seguintes: economia dominada pelo sistema financeiro e pelo investimento à escala global; processos de produção flexíveis e multilocais; baixos custos 
de transporte; revolução nas tecnologias de informação e de comunicação;desregularão das economias estatais; preeminência das agenciais financeiras multilaterais ( 2002 ,p. 31).

Por isto nos interessou ter como objetivo neste texto analisar os cadernos de formação do PNAIC, em meio a esta dinâmica de eixo econômico. O caminho teórico-metodológico adotado foi à abordagem qualitativa, uma vez que analisamos os cadernos de um programa de formação destinado á professores, em os cadernos defendem uma concepção de formação, que neste caso, supomos ser para a inserção e preparação para o mercado competitivo. A analise de conteúdos de Bardin (2002), que se consiste em "descobrir os diferentes núcleos de sentido que constituem a comunicação, e posteriormente, realizar o seu reagrupamento em classes ou categorias empíricas". Significa o entendimento desde programa (objeto) a parti dos diversos fatores que o circunscrevem.

Neste perspectiva é fundamental o posicionamento teórico-metodológico e um instrumento de coleta que seja capaz de fornecer elementos possíveis de se manter diálogos. Luna (2000, p. 14) decorre sobre este posicionamento: "O reconhecimento do poder relativo da metodologia tem por traz outra decorrência da evolução do pensamento epistemológico: a substituição da busca da verdade pela tentativa de aumentar o poder explicativo das teorias". E nesta tentativa de explicar este fenômeno educativo presente nesta ciência social, adotaremos a abordagem qualitativa, o que segundo Chizzotti:

O termo qualitativo implica uma partilha densa com pessoas, fatos e locais que constituem objetos de pesquisa, para extrair desse convívio os significados visíveis e latentes que somente são perceptíveis a uma atenção sensível e, após esse tirocínio, o autor interpreta e traduz em um texto, zelosamente escrito, com perspicácia e competência cientifica, os significados patentes ou ocultos do seu objeto de pesquisa (2003, p. 02).

Então diante deste Pacto, se faz necessário discutirmos em quais referenciais os seus cadernos estão pautados. O PNAIC é executado a partir de um compromisso formal assumido pelos entes federados (Governo Federal, Distrito Federal, Estados e Municípios). A portaria 867 de julho de 2012 define além da meta de se alfabetizar até os oito anos de idade, regulamenta também os objetivos das ações do programa, logo há esta possibilidade dos estados e municípios aderirem ao programa na integra (comprometimento com a meta juntamente adesão às ações) ou pode ser aderido parcialmente (apenas comprometimento da meta). Acontece que o município pode aderir apenas o comprometimento do alcance da meta e já dispor de investimentos na alfabetização nos primeiros anos da educação fundamental; outra coisa é, por anuência das partes, aderir apenas à meta e não ter em sua rede algum trabalho que coadune para que as crianças estejam alfabetizadas até os oito anos de idade, com certeza depreenderá mais energia desde ente, principalmente se atentarmos para o fato que a educação é um direito subjetivo, é atributo de todos, posto na Constituição Federal (1988). 
Este critério por adesão, permiti- nos supor dois elementos: o primeiro é que ele é necessário, mas não obrigatório, adere quem quer, o que de alguma maneira torna a necessidade da alfabetização secundária; o segundo é que a iniciativa para solucionar um problema desta natureza surgiu de um governo, o que não garante a permanecia ao findar do mandato da presidente. Estes dois elementos remontam que a alfabetização precisa ser encarada como efetivamente fundamental e permanente, concebida sim como política de Estado. Para todo caso, a portaria estabelece as responsabilidades na adesão ao Pacto. Segue a quadro I abaixo:

\begin{tabular}{|c|l|}
\hline $\begin{array}{c}\text { OBJETIVOS } \\
\text { DAS AÇÕES }\end{array}$ & $\begin{array}{l}\text { I - Garantir que todos os estudantes dos sistemas públicos de ensino estejam } \\
\text { alfabetizados, em Língua Portuguesa e em Matemática, até o final do } 3^{\circ} \text { ano do ensino } \\
\text { fundamental; }\end{array}$ \\
\cline { 2 - 3 } & II - reduzir a distorção idade-série na Educação Básica; \\
\cline { 2 - 3 } & III - melhorar o Índice de Desenvolvimento da Educação Básica (IDEB); \\
\cline { 2 - 3 } & IV - contribuir para o aperfeiçoamento da formação dos professores alfabetizadores; \\
\cline { 2 - 3 } & $\begin{array}{l}\text { V - construir propostas para a definição dos direitos de aprendizagem e desenvolvimento } \\
\text { das crianças nos três primeiros anos do ensino. }\end{array}$ \\
\hline \multirow{2}{*}{$\begin{array}{c}\text { INCUBS ENTES } \\
\text { FEDERADOS }\end{array}$} & $\begin{array}{l}\text { I. Alfabetizar todas as crianças em língua portuguesa e em } \\
\text { matemática. }\end{array}$ \\
\cline { 2 - 3 } & $\begin{array}{l}\text { II. Realizar avaliações anuais universais, aplicadas pelo } \\
\text { Inep, junto aos concluintes do } 3^{\circ} \text { ano do ensino } \\
\text { fundamental. }\end{array}$ \\
\hline & $\begin{array}{l}\text { III. No caso dos estados, apoiar os municípios que tenham } \\
\text { aderido às Ações do Pacto, para sua efetiva } \\
\text { implementação. }\end{array}$ \\
\hline
\end{tabular}

QUADRO I elaborada pelas autoras com base na portaria do MEC, Art. 5 da portaria $\mathrm{N}^{\circ}$ 867, 2012).

Sob estas condições, que de maneira geral, o Programa do governo de Dilma Rousseff, prevê a alfabetização por meio de um currículo mínimo, concebe o direito de aprendizagem dos alunos por via do ensino de português e matemática como posto na primeira incumbência.

\section{O PNAIC e a concepção de educação}

O material de formação dos professores alfabetizadores é aberto, disponibilizado na internet: Cadernos de Alfabetização em língua portuguesa; Cadernos de Alfabetização Matemática; um de Formação de professores; Apresentação; Avaliação; Cadernos do Campo; Educação Especial. Contudo, para esta pesquisa privilegiamos a analise os Cadernos de Alfabetização em Língua Portuguesa, Cadernos do Campo, Educação Especial. Em razão de, espera- se que estes últimos contemplem a diversidade de alunos presente nos anos iniciais e os primeiros estão presentes desde lançamento do PNAIC. Sobre os objetivos dos cadernos temos a quadro II abaixo:

\begin{tabular}{|c|c|c|c|c|c|c|}
\hline $\begin{array}{c}\text { Objetivos } \\
\text { dos } \\
\text { cadernos }\end{array}$ & ANO & ANO I & ANO II & ANO III & $\begin{array}{c}\text { CADERNOS DO } \\
\text { CAMPO }\end{array}$ & $\begin{array}{c}\text { Educação } \\
\text { Especial }\end{array}$ \\
\hline $\mathbf{1}^{\mathbf{a}}$ & UNIDADE & $\begin{array}{c}\text { Refletir sobre a } \\
\text { possibilidade }\end{array}$ & $\begin{array}{c}\text { Iremos tratar da } \\
\text { importância de }\end{array}$ & $\begin{array}{c}\text { Buscaremos de } \\
\text { modo }\end{array}$ & $\begin{array}{c}\text { Refletir sobre } \\
\text { alguns princípios }\end{array}$ & $\begin{array}{c}\text { Buscar } \\
\text { discutir sobre }\end{array}$ \\
\hline
\end{tabular}




\begin{tabular}{|c|c|c|c|c|c|c|}
\hline & & $\begin{array}{c}\text { real de } \\
\text { desenvolviment } \\
\text { o de práticas de } \\
\text { alfabetização } \\
\text { baseadas na } \\
\text { inclusão e no } \\
\text { respeito à } \\
\text { heterogeneidade. }\end{array}$ & $\begin{array}{l}\text { o currículo de } \\
\text { alfabetização } \\
\text { possuir clareza } \\
\text { quanto aos } \\
\text { direitos de } \\
\text { aprendizagem } \\
\text { das crianças e } \\
\text { de buscar uma } \\
\text { progressão do } \\
\text { ensino e da } \\
\text { aprendizagem } \\
\text { ao longo dos } \\
\text { três anos } \\
\text { iniciais }\end{array}$ & $\begin{array}{l}\text { compartilhado, } \\
\text { refletir sobre } \\
\text { alguns } \\
\text { princípios } \\
\text { gerais que } \\
\text { consideramos } \\
\text { fundamentais } \\
\text { para orientar o } \\
\text { trabalho } \\
\text { docente e que } \\
\text { se expressam no } \\
\text { ensino dos anos } \\
\text { iniciais no } \\
\text { cotidiano da } \\
\text { sala de aula. }\end{array}$ & $\begin{array}{c}\text { gerais a respeito } \\
\text { dos três grandes } \\
\text { temas propostos: } \\
\text { currículo, } \\
\text { concepções de } \\
\text { alfabetização e } \\
\text { avaliação no } \\
\text { primeiro ciclo. }\end{array}$ & \multirow[t]{2}{*}{$\begin{array}{c}\text { educação } \\
\text { especial na } \\
\text { perspectiva da } \\
\text { educação } \\
\text { inclusiva para } \\
\text { ampliar, } \\
\text { potencializar } \\
\text { as } \\
\text { possibilidades } \\
\text { de ensino e } \\
\text { orientar a } \\
\text { utilização de } \\
\text { jogos e } \\
\text { brincadeiras } \\
\text { em contextos } \\
\text { inclusivos de } \\
\text { alfabetização. }\end{array}$} \\
\hline $2^{a}$ & UNIDADE & 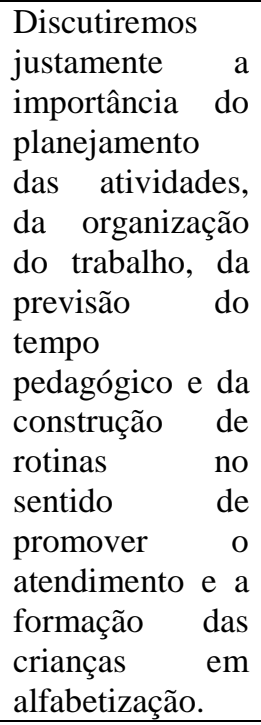 & $\begin{array}{l}\text { A organização } \\
\text { do } \\
\text { planejamento e } \\
\text { da rotina no } \\
\text { ciclo de } \\
\text { alfabetização na } \\
\text { perspectiva do } \\
\text { letramento é o } \\
\text { tema principal } \\
\text { dessa unidade }\end{array}$ & $\begin{array}{l}\text { O planejamento } \\
\text { do ensino na } \\
\text { alfabetização é } \\
\text { o tema principal } \\
\text { dessa unidade. }\end{array}$ & $\begin{array}{l}\text { O pressuposto } \\
\text { principal é o do } \\
\text { reconhecimento } \\
\text { da diversidade de } \\
\text { experiências, com } \\
\text { garantia de } \\
\text { aprendizagem. }\end{array}$ & \\
\hline $3^{a}$ & UNIDADE & $\begin{array}{l}\text { Nosso propósito } \\
\text { é discutir sobre a } \\
\text { aprendizagem } \\
\text { do Sistema de } \\
\text { Escrita } \\
\text { Alfabética }\end{array}$ & $\begin{array}{c}\text { Discutiremos } \\
\text { sobre o Sistema } \\
\text { de Escrita } \\
\text { Alfabética } \\
\text { (SEA), } \\
\text { refletindo sobre } \\
\text { suas } \\
\text { propriedades e } \\
\text { convenções e } \\
\text { sobre o seu } \\
\text { processo de } \\
\text { apropriação } \\
\text { pelos } \\
\text { aprendizes } \\
\end{array}$ & \begin{tabular}{ll}
\multicolumn{2}{l}{ Discutir sobre a } \\
apropriação do \\
Sistema de \\
Escrita \\
Alfabética \\
(SEA)
\end{tabular} & $\begin{array}{c}\text { Discutir aspectos } \\
\text { da apropriação do } \\
\text { Sistema de Escrita } \\
\text { Alfabética (SEA), } \\
\text { refletindo sobre } \\
\text { suas propriedades } \\
\text { e convenções. }\end{array}$ & \\
\hline $4^{a}$ & UNIDADE & $\begin{array}{l}\text { Refletir sobre a } \\
\text { ludicidade na } \\
\text { sala de aula. }\end{array}$ & $\begin{array}{l}\text { Teremos como } \\
\text { foco a presença } \\
\text { do lúdico na } \\
\text { sala de aula. }\end{array}$ & $\begin{array}{l}\text { Apresentar aos } \\
\text { professores } \\
\text { algumas } \\
\text { maneiras de } \\
\text { assegurar que a } \\
\text { brincadeira } \\
\text { continue } \\
\text { presente em } \\
\text { suas salas, sem } \\
\text { que isso } \\
\text { signifique } \\
\text { deixar de tratar } \\
\text { de conteúdos }\end{array}$ & $\begin{array}{l}\text { Discutir sobre a } \\
\text { importância do } \\
\text { lúdico no } \\
\text { processo de } \\
\text { alfabetização para } \\
\text { as crianças dos } \\
\text { povos do campo. }\end{array}$ & \\
\hline
\end{tabular}




\begin{tabular}{|c|c|c|c|c|c|}
\hline & & & & $\begin{array}{l}\text { fundamentais } \\
\text { para as crianças }\end{array}$ & \\
\hline $5^{a}$ & UNIDADE & $\begin{array}{l}\text { Retomar } \\
\text { discussão sobre } \\
\text { a importância de } \\
\text { se trabalhar } \\
\text { textos em sala } \\
\text { de aula e de } \\
\text { articular esse } \\
\text { trabalho com os } \\
\text { diferentes eixos } \\
\text { relativos ao } \\
\text { componente } \\
\text { curricular } \\
\text { Língua } \\
\text { Portuguesa, } \\
\text { principalmente } \\
\text { com o processo } \\
\text { de alfabetização. }\end{array}$ & $\begin{array}{l}\text { Refletiremos } \\
\text { sobre a } \\
\text { importância da } \\
\text { leitura e da } \\
\text { produção de } \\
\text { textos na } \\
\text { alfabetização. }\end{array}$ & $\begin{array}{l}\text { Discutir o } \\
\text { trabalho com os } \\
\text { diversos } \\
\text { gêneros textuais } \\
\text { em sala de aula } \\
\text { e } \\
\text { apresentaremos } \\
\text { algumas } \\
\text { estratégias para } \\
\text { a seleção e } \\
\text { utilização dos } \\
\text { textos em } \\
\text { turmas de } \\
\text { alfabetização. }\end{array}$ & $\begin{array}{l}\text { Refletir sobre a } \\
\text { importância da } \\
\text { leitura e produção } \\
\text { de textos na } \\
\text { alfabetização. } \\
\text { Nesse caderno, } \\
\text { direcionado para } \\
\text { as escolas do } \\
\text { campo. }\end{array}$ \\
\hline $6^{a}$ & UNIDADE & $\begin{array}{l}\text { Refletir sobre } \\
\text { formas de } \\
\text { organização do } \\
\text { trabalho } \\
\text { pedagógico, } \\
\text { especialmente } \\
\text { sobre os projetos } \\
\text { didáticos e } \\
\text { sequências } \\
\text { didáticas na } \\
\text { alfabetização. }\end{array}$ & $\begin{array}{l}\text { Refletir sobre o } \\
\text { planejamento } \\
\text { do ensino, na } \\
\text { busca de } \\
\text { garantirmos a } \\
\text { alfabetização } \\
\text { das crianças na } \\
\text { perspectiva do } \\
\text { letramento e da } \\
\text { integração entre } \\
\text { diferentes } \\
\text { componentes } \\
\text { curriculares. }\end{array}$ & $\begin{array}{l}\text { Intenta-se não } \\
\text { somente } \\
\text { conhecer, } \\
\text { discutir, mas } \\
\text { perceber } \\
\text { possibilidades } \\
\text { de práticas } \\
\text { pedagógicas, } \\
\text { que envolvem } \\
\text { diversas áreas } \\
\text { de conhecimentos, } \\
\text { tendo como } \\
\text { foco principal a } \\
\text { área da } \\
\text { linguagem. }\end{array}$ & $\begin{array}{l}\text { Refletir } \\
\text { formas } \\
\text { organização de } \\
\text { trabalho } \\
\text { pedagógico, } \\
\text { buscamos, neste } \\
\text { caderno, discutir } \\
\text { sobre } \\
\text { especificidades do } \\
\text { espaço escolar do } \\
\text { campo e os modos } \\
\text { como tais } \\
\text { especificidades } \\
\text { podem } \\
\text { consideradas no } \\
\text { planejamento. }\end{array}$ \\
\hline $7^{a}$ & UNIDADE & $\begin{array}{c}\text { O foco, } \\
\text { portanto, é no } \\
\text { modo como } \\
\text { tratar das } \\
\text { diferenças na } \\
\text { perspectiva de } \\
\text { promover as } \\
\text { aprendizagens, } \\
\text { garantindo os } \\
\text { direitos de } \\
\text { aprendizagem a } \\
\text { todos. }\end{array}$ & $\begin{array}{c}\text { Discutiremos } \\
\text { sobre o } \\
\text { tratamento da } \\
\text { heterogeneidade } \\
\text { de } \\
\text { conhecimentos } \\
\text { dos aprendizes } \\
\text { no processo de } \\
\text { alfabetização. }\end{array}$ & $\begin{array}{l}\text { Discutiremos o } \\
\text { tratamento da } \\
\text { heterogeneidade } \\
\text { em nossas } \\
\text { turmas de final } \\
\text { do primeiro } \\
\text { ciclo, assim } \\
\text { como a } \\
\text { necessidade de } \\
\text { praticarmos um } \\
\text { ensino ajustado, } \\
\text { que atenda as } \\
\text { necessidades } \\
\text { dos alunos }\end{array}$ & $\begin{array}{l}\text { Discutiremos } \\
\text { sobre } \\
\text { necessidade de } \\
\text { garantir } \\
\text { alfabetização no } \\
\text { campo com foco } \\
\text { em práticas } \\
\text { inclusivas que } \\
\text { valorizem } \\
\text { diferentes } \\
\text { percursos } \\
\text { conhecimentos } \\
\text { dos estudantes de } \\
\text { salas } \\
\text { multisseriadas. }\end{array}$ \\
\hline $8^{a}$ & UNIDADE & $\begin{array}{c}\text { Retomar [...] } \\
\text { algumas } \\
\text { reflexões sobre a } \\
\text { progressão } \\
\text { escolar no ciclo } \\
\text { de alfabetização, } \\
\text { na perspectiva } \\
\text { da não } \\
\text { reprovação, mas } \\
\text { com ações }\end{array}$ & $\begin{array}{l}\text { Retomados [...] } \\
\text { algumas } \\
\text { reflexões sobre } \\
\text { o que é } \\
\text { necessário para } \\
\text { se garantir a } \\
\text { progressão e a } \\
\text { continuidade } \\
\text { das } \\
\text { aprendizagens }\end{array}$ & $\begin{array}{l}\text { Iremos retomar } \\
\text { os temas que já } \\
\text { foram tratados } \\
\text { ao longo das } \\
\text { demais } \\
\text { unidades do } \\
\text { curso, tendo } \\
\text { como foco a } \\
\text { reflexão sobre a } \\
\text { progressão }\end{array}$ & $\begin{array}{l}\text { Retomar com o } \\
\text { intuito de } \\
\text { sistematizarmos } \\
\text { algumas reflexões } \\
\text { sobre a avaliação } \\
\text { e a progressão } \\
\text { escolar no ciclo de } \\
\text { alfabetização, na } \\
\text { perspectiva da não } \\
\text { reprovação. }\end{array}$ \\
\hline
\end{tabular}




\begin{tabular}{|c|c|c|l|l|l|}
\hline & $\begin{array}{c}\text { concretas que } \\
\text { promovam } \\
\text { condições de } \\
\text { avanços na } \\
\text { aprendizagem } \\
\text { das crianças. }\end{array}$ & $\begin{array}{l}\text { para } \\
\text { construção dos } \\
\text { conhecimentos } \\
\text { por todas as } \\
\text { crianças. }\end{array}$ & $\begin{array}{l}\text { escolar e aliação, } \\
\text { avas. }\end{array}$ & \\
& & & \\
& & & \\
\end{tabular}

QUADRO II elaborado pelas autoras com base no material disponibilizado nos Cadernos de Formação (2012).

Verificamos no quadro II que os objetivos de cada unidade privilegiam a prática docente para melhorar a alfabetização, observamos que no $2^{\mathrm{a}}$ ano as questões que se aproximam com práticas que respeitem a heterogeneidade ocorreram nas unidades 6,7 e 8 ; no $1^{\mathrm{a}}$ ano 1,5 e 7 e no $3^{\circ}$ ano o caderno trouxe como objetivos nas duas unidades: 6 e 7. Nos Cadernos do Campo a abordagem esteve presente 3 vezes dos oito cadernos. O Caderno Especial trouxe a inclusão para pessoas com deficiência no titulo do Caderno: A Alfabetização de Crianças com deficiência: Uma Proposta Inclusiva, para integração das crianças com deficiência. De modo geral, com base neste quadro sobre os objetivos dos Cadernos do PNAIC, a temática sobre a diversidade é presente nos Cadernos do PNAIC, o que fortalece e favorece as secretárias de educação no percurso dos entes federados para atingir a meta 5 do Plano Nacional de Educação.

Ainda assim no analisando o quadro II, verifica-se que mesmo o programa abordando em suas unidades a inclusão, os alunos do campo e alunos com deficiência, ocorre uma intensa preocupação para a aquisição dos conhecimentos em língua portuguesa. As demais disciplinas são abordadas como mediadoras em direção à meta de alfabetização, por isso que percebemos no quadro II a utilização das demais áreas auxiliando a efetivação da alfabetização, utiliza-se as demais áreas do conhecimento como suporte. Á vista disso, o primeiro objetivo das ações do PNAIC é garantir que todos os estudantes dos sistemas públicos de ensino estejam alfabetizados, em Língua Portuguesa e em Matemática, até o final do $3^{\circ}$ ano do ensino fundamental. Assim analisando o PACTO diante destas nuances, nos aproximamos do entendimento de que há uma centralização dos resultados obtidos nas avaliações de português e matemática, onde para garantir o êxito do programa foi instituído a Avaliação Nacional da Alfabetização, a ANA, além da já existente Provinha Brasil, que avalia os alunos no inicio e no final do segundo ano do ciclo de alfabetização, bem como ao Sistema de Avaliação da Educação Básica (Saeb).

\section{O PNAIC no contexto de globalização}

$\mathrm{Na}$ globalização as políticas educacionais são apresentadas com esta dicotomia para a sociedade, no sentido que sugere formas diferentes de garantir os direitos de aprendizagens e 
inclusão, no entanto, são legitimadas por avaliações em larga escala com centralização em português e matemática. Deste modo trago Èmile Durkheim situando a educação que:

É antes de tudo o meio pelo qual a sociedade renova eternamente as condições da sua própria existência. A sociedade só pode viver se existir uma homogeneidade suficiente entre os seus membros. A educação perpetua e reforça esta homogeneidade ao fixar de antemão na alma da criança as semelhanças essenciais que a vida coletiva supõe. Porém, ao mesmo tempo, qualquer cooperação seria impossível sem uma certa diversidade. A educação garante a continuidade desta necessária diversidade diversificando-se e especializando-se a si mesma (p.108-109).

Concordamos com Durkheim neste sentido em que se refere à educação, principalmente quando observamos as atuais políticas educacionais forjando um currículo comum no pais, mesmo constando da garantia de uma parte diversificada, prevista também na Diretrizes Curriculares Nacionais para o Ensino Fundamental (DCNEF) instituía desde de 1998, em seu Art. 3, inciso II, "as Escolas deverão explicitar o reconhecimento da identidade pessoal de alunos, professores e outros profissionais e a identidade de cada unidade escolar e de seus respectivos sistemas de ensino“.

Desde modo, este movimento aparentemente contraditório presente na educação tem um caráter hegemônico, pois confere margem para dispersarmos a ideia de preservação da natureza centralizadora e hegemônica das propostas curriculares dos programas utilizando-se de pretextos de respeito à diversidade, corroboram para um único modelo. Um exemplo destas propostas paradoxais na educação: a DCNEF (1998) e a emenda constitucional $\mathrm{N}^{\circ} 12.796$, de 4 de abril de 2013 que altera a própria na LDB (1996) no Art. $3^{\text {o, }}$, XII - na consideração com a diversidade étnico-racial e as várias avaliações educacionais em larga escala que priorizam o português e a matemática. Em quais momentos os apontamentos do DCNEF e avaliações se cruzam?. Avaliações são necessárias ao próprio caminho de oferecer uma educação de qualidade, para isto é preciso resgatar aspectos presentes na realidade.

Então o que aparentemente parece ser conflituoso e contraditório, sobre o programa contemplar diferentes seguimentos, mas que tem suas raízes na centralização do currículo, se aproxima do Durkhein tratava anteriormente sobre a educação garantir a continuidade desta necessária diversidade, diversificando-se e especializando-se a si mesma. Este também é um pouco do debate que Friedman, o pai do neoliberalismo faz, ele coloca que a intervenção do estado como o principal garantidor da educação é como um empecilho ao desenvolvimento do individuo. O que Friedman (1962) faz é uma critica a possível centralidade que a atuação do governo pode provocar impedindo o desenvolvimento dos indivíduos, segundo ele a educação proposta pelo estado limita o poder de escolha livre do individuo. A critica que Friedman realizada é sobre "as atividades do governo que estão em grande parte limitadas à instrução“. Educação geral dos cidadãos. "Uma sociedade democrática e estável [desejada pelo estado] é impossível sem um grau mínimo de 
alfabetização e conhecimento por parte da maioria dos cidadãos e sem a ampla aceitação de algum conjunto de valores“ (1962 p. 44).

Os cadernos do PNAIC sinalizam a inclusão da diversidade, mas que concebe a estrutura da educação pautada fundamentalmente por conteúdos mínimos, o que além de centralizar os currículos escolares, prepara com o mínimo os sujeitos para assumir as posições que garante apenas a sobrevivência, a manutenção. Parafraseando Durkhein, outrora já mencionado, por meio da diversificação da diversidade a educação garante a continuidade necessária a preservar antigas estruturas. Essa centralização esta posta sobre uma estrutura composta por dois tipos de lutas em intensidades diferentes: temos minoritariamente as lutas locais, que fazem valer suais características tentando se tornar visíveis e valorizadas e; majoritariamente temos os preceitos a nível global com um caráter hegemônico, lançando os valores globalmente prestigiados. Santos (1995, p.21):

Privilegio, [...], uma definição de globalização mais sensível às dimensões sociais, políticas e culturais. Aquilo que habitualmente designamos por globalização são, de fatos, conjuntos diferenciados de relações sociais; diferentes conjuntos de relações sociais dão origem a diferentes fenômenos de globalização.

Da mesma maneira, a compreensão de educação na cultura da globalização esclarece que aquilo que ganha notoriedade é a expressão de vivencia sociais. O que define quais relações sociais se denominarão integrantes da globalização é o regime neoliberal de regulamentação de mercado, que pode situar o poder de influencia destas relações na rede de comunicação. Um exemplo é o caso de sucesso da -feijoada- no mundo, vende! Isto é o que Boaventura de Sousa Santos conceitua como sendo o Localismo Globalizado.

O exemplo do programa do governo do estado de Pernambuco Ganhe o Mundo. Destinado a selecionar estudantes do ensino médio para realizarem intercambio em países como o Canadá e Estados Unidos. É como se por meio desta iniciativa, o Governo provocasse os avanços legitimando a credibilidade dos seus alunos frente aos potenciais países. Este fenômeno se denomina Globalismo Localizado. A globalização impacta na estrutura visível como na subjetividade dos indivíduos. Sobre isto Hall (2011, p.06):

O impacto das revoluções culturais sobre as sociedades globais e a vida cotidiana local, no
final do séc. XX pode parecer significativo e tão abrangente que justifique a alegação de
que a substantiva expansão da - cultura" que experimentamos, não tenha precedentes. Mas
a menção do seu impacto na - vida interiorll lembra-nos de outra fronteira que precisa ser
mencionada. Isto relaciona-se á centralidade da cultura na constituição da subjetividade, da
própria identidade, e da pessoa como um ator social.

São nestas condições de localismo globalizado e globalismo localizado que as políticas educacionais são incorporadas pelos sujeitos em que se permanece valorizando as diferentes culturas com o víeis centralizador o poder neoliberal. É importante saber o que Santos (2002, p.73) ressalta que "Umas das armadilhas da globalização neoliberal consiste em acentuar simbolicamente 
a distinção entre o local e o global e ao mesmo tempo destruí-la ao nível dos mecanismo reais da economia“. Em decorrência disto Hall (2011, p.16) colabora:

Os efeitos do processo de — globalização — enfraquecendo a relativa autonomia dos estados nacionais na determinação das políticas culturais em seus próprios territórios soberanos e aumentando as pressões por políticas do tipo —céu aberto, de internacionalização dos mercados culturais — têm tido um papel cada vez mais significativo, uma vez que está ocorrendo uma tendência, à qual não se tem dado muita importância, de retomada da monopolização pelas transnacionais globais.

Como verificamos os referenciais que norteiam as políticas educacionais, no contexto atual, esta a serviço de um projeto de sociedade neoliberal, promovendo e exercitando a cultura do mercado. O debate da alfabetização é retomado pela necessidade da globalização, não resgatando elementos da diversidade, contrariamente se utiliza os mais variados artifícios para tratar da necessidade da não alfabetização. Ou melhor torna relevante a alfabetização por interesse de mercado.

\section{Considerações:}

Sobre o material analisado, além da centralização do currículo nos cadernos do PNAIC, na maioria da vezes, os sujeitos da escola não têm o retorno dos resultados, fator que contribui para o distanciamento entre avaliações educacionais e a escola. Neste sentido, a avaliação não contempla as diversidades, evidenciando a ênfase na qualificação mercado de trabalho. Posto que se o problema é antigo, o interesse político de investir na alfabetização se origina na globalização capitalista, que envolve como Boaventura de Souza Santos aspectos sociais, políticas e culturais. Uma premissa utilizada por Boaventura de Souza Santos com respeito à concepção de direito ser fragmentada por ser concebida como universal:

É que todas as culturas são incompletas e problemáticas nas suas concepções de dignidade humana. A incompletude provém da própria existência de uma pluralidade de culturas, pois, se cada cultura fosse tão completa como se julga, existiria apenas uma só cultura. A ideia de completude está na origem de um excesso de sentido de que parecem enfermar todas as culturas, e é por isso que a incompletude é mais facilmente perceptível do exterior, a partir da perspectiva de outra cultura. Aumentar a consciência de incompletude cultural até ao seu máximo possível é uma das tarefas mais cruciais para a construção de uma concepção multicultural de direitos humanos (Santos, 1995, p.29).

Esta tarefa proposta por Santos para a constituição das sociedades, possibilitando cada cultura institucionalizar suas crenças e valores pensando na normalidade que é ser incompleto e diferente, talvez seja um desafio também ao planejamento de políticas educacionais neste pais, quando pensam os sujeitos das escolas. "Porque temos o direito de ser iguais quando a diferença nos inferioriza e ser diferentes quando a igualdade no descaracteriza“(SANTOS, p.75).

\section{Referenciais:}


BARDIN, Laurence. Análise de conteúdo. 3. Ed. Portugal: Ed. 70, 2004. BRASIL.

BOURDIEU, Pierre. O poder simbólico/ Pierre Bourdieu; tradução Fernando Tomaz (português de Portugal) $-6^{\mathrm{a}}$ ed. - Rio de Janeiro; Bertrand Brasil, 2003. 322p.

Chizzotti, Antonio. Pesquisa qualitativa em ciências sociais e humanas. Revista Portuguesa em Educação, 2003, 16(2) pp 221-236, universidade do Ninho Disponível em: www.unisc.br/portal/upload/com_arquivo/1350495029.pdf acesso em: 06/08/2015.

DURKHEIM, Émile. Educação e Sociologia. São Paulo: Melhoramentos, 1973.

FRIEDMAN, Milton. Capitalismo e Liberdade. Ed. Abril. 1962. EUA. Disponível em: http://www.ufrgs.br/daeca/wp/wp-content/uploads/2009/03/capitalismo-e-liberdade.pdf Acesso em 10/08/ 2015.

BRASIL. Saeb. Inep. Disponível em: http://portal.inep.gov.br/web/guest/caracteristicas-saeb . Acesso em: 10/08/2015

. Provinha Brasil. Inep. Disponível em: http://provinhabrasil.inep.gov.br/. Acesso em: $10 / 08 / 2015$

. Emenda Constitucional lei $n^{0}$ 12.796, de 4 de abril de 2013. Disponível em: http://www.planalto.gov.br/ccivil_03/_ato2011-2014/2013/lei/112796.htm\#art1. Acesso em: 10/08/ 2015.

Constituição da República Federativa do Brasil de 1988. Disponível em: http://www.planalto.gov.br/ccivil_03/constituicao/constituicao.htm. Acesso em: 10/08/ 2015.

Pacto Nacional pela Alfabetização na Idade. Disponível em: http://pacto.mec.gov.br/documentos-importantes. Acesso em: 20/08/ 2015.

Plano Nacional de Educação (PNE). Disponível em: http://www.planalto.gov.br/ccivil_03/_ato2011-2014/2014/lei/113005.htm. Acesso em: 20/08/ 2015.

Lei de Diretrizes e Bases da Educação Nacional (LDB). Disponível em: http://www.planalto.gov.br/CCIVIL_03/leis/L9394.htm . Acesso em: 15/08/ 2015.

Diretrizes Curriculares Nacionais para o Ensino Fundamental (DCNEF). Disponível em: portal.mec.gov.br/cne/arquivos/pdf/PCB0498.pdf. Acesso em: 15/08/ 2015.

LUNA. Sergio Vasconcelos. Planejamento de Pesquisa - uma introdução- Elementos para uma Analise Metodologia. Educ. 2000. SP.

SANTOS, Boaventura de Souza Santos [org]. A globalização e as ciências sociais. Ed. 2. Cortez. São Paulo. 2002.

SANTOS, Boaventura de Sousa. As tensões da modernidade. Fórum Mundial Social: biblioteca das alternativas, agosto de 2002. Disponível em: http://www.forumsocialmundial.org.br/dinamic/boaventura.php 